\title{
Préstamos léxicos del catalán: contraste entre el DRAE-1992 y el DRAE-2001*
}

MARTA PRAT SABATER

Universidad Autónoma de Barcelona

\section{INTRODUCCIÓN}

Cualquier nueva edición del diccionario académico comporta por parte de filólogos y usuarios afines al trabajo lexicográfico el afán de conocer los cambios que se han producido relacionados con la corrección y actualización de la obra y, lo que es más importante, con su acomodación a las necesidades contemporáneas de la lengua española que, como cualquier otra, «tiene la capacidad de adaptarse a los desafíos sociales, culturales, históricos y científicos que se plantean», como manifiesta Gutiérrez Cuadrado (2001-2002: 309) en su reseña a la vigésima segunda edición. En las conclusiones de este trabajo, centrado más en valorar la concepción del diccionario que en proporcionar una lista de errores, como comenta repetidamente el autor, se destaca de forma positiva «el cambio de rumbo» que ha experimentado, al mismo tiempo que se insiste en la necesidad de optar por «otro rumbo distinto», cuyos objetivos principales sean la revisión de las definiciones, la inclusión de ejemplos y el desembarazo de arcaísmos y palabras caídas en desuso que ni son suficientes para cubrir la carencia de un diccionario histórico completo, ni son adecuados como contenido de una obra representativa del uso actual. Se comenta también, de paso, que «deberían corregirse las etimologías erróneas» y que estaría bien fijar «el origen inmediato y no la etimología lejana» (2001-2002: 318), aspectos en los que deseo profundizar en esta comunicación y que, para ello, traslado al campo de los préstamos del catalán.

* El trabajo que conlleva esta comunicación ha sido subvencionado por el Comissionat per a Universitats i Recerca (2001 SGR-00151). 
En el prólogo a esta vigésima segunda edición del Diccionario de la lengua española de la Real Academia (en adelante $D R A E$ ), como novedad, se informa de que «se han uniformado los paréntesis etimológicos, especialmente para regularizar el orden de los elementos contenidos en ellos» (DRAE-2001: xxx). Las modificaciones, según esta nota, son exclusivamente formales. Conviene indagar si se observan, asimismo, variaciones de contenido etimológico.

El contraste entre las dos últimas ediciones del DRAE (1992 y 2001) en lo referente a los préstamos del catalán puede ser esencial para comprobar sobre el terreno etimológico, por un lado, la ejecución de los cambios formales contemplados en el prólogo, y, por otro, los de contenido, que son sumamente importantes para el avance de los estudios sobre los préstamos incorporados a la lengua española y aceptados por los académicos. Para la consecución de estos dos objetivos se adoptan como punto de partida las dos últimas ediciones en CD-ROM de esta obra lexicográfica-indispensables para la localización rápida del corpus- y el trabajo que sobre la primera de ellas presenté hace cuatro años en el $v$ Congreso Internacional de Historia de la Lengua Española, celebrado en la Universidad de Valencia (Prat Sabater 2000).

\section{CAMBios Formales}

Se ha podido comprobar que se ha producido una regularización del orden de los elementos incluidos en los paréntesis etimológicos, como se advierte en el prólogo de la obra, pero debería asimismo precisarse que el cambio formal es incluso más amplio y está relacionado con los términos escogidos para informar sobre el grado de fiabilidad de las hipótesis que se proponen. Es posible distinguir, por tanto, los siguientes tipos de sistematización:

\subsection{Orden de datos etimológicos}

Cuando se propone más de un estadio etimológico, siempre se empieza la redacción de la hipótesis por el étimo más inmediato al español. ${ }^{1}$ En la edición de 1992, esta opción convivía con otra expresada en orden invertido (del étimo último al inmediato) que, sin lugar a dudas, era la mayoritaria:

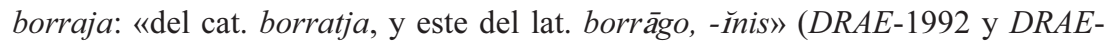
2001);

proel: «del lat. prora, a través del cat. proer» (DRAE-1992),

1 Dentro del grupo de los préstamos del catalán, sólo se ha hallado una excepción en el lema niel: «del lat. nigellus, dim. del niger, negro, seguramente a través del cat. niell» (DRAE-1992 y DRAE-2001). 
«del cat. proer, y este del lat. prora» (DRAE-2001);

elmete: «del germ. helm, a través del fr. ant. healmet, elmet, o del cat. elmet» (DRAE1992),

«del fr. ant. healmet, elmet o cat. elmet, y estos del franco helm» (DRAE-2001).

\subsection{Fiabilidad de la hipótesis etimológica}

Es posible establecer, en ambas ediciones, tres grupos de préstamos según si la intervención de la lengua transmisora es más o menos probable. Pueden obtenerse voces de procedencia catalana indiscutible (catalanismos seguros), probable (catalanismos no seguros), o con mera información comparativa referente al catalán que, como se comprobará más adelante, puede sugerir una posible relación de transferencia. Se estudiarán, a continuación, los cambios formales que se han producido en cada uno de estos grupos:

2.2.1. Voces de procedencia catalana indiscutible: la estructura de la hipótesis etimológica de los lemas que con toda seguridad se han importando del catalán no se ha modificado en la última edición del $D R A E$. Tanto en esta como en la anterior, se encabeza con la preposición de:

forastero, ra: «del cat. foraster» (DRAE-1992 y DRAE-2001);

mercería: «del cat. merceria» (DRAE-1992 y DRAE-2001).

2.2.2. Voces de procedencia catalana probable: la transferencia catalana propuesta se presenta como no segura en muy pocos casos. En la edición de 1992, este tipo de descripción etimológica era bastante heterogénea. Probablemente, quizá y seguramente eran los adverbios que solían utilizarse para expresar este grado de probabilidad, precedidos en ocasiones por de or. inc. (de origen incierto). En la edición de 2001, se ha producido una sistematización. Se emplea con exclusividad el adverbio quizá: ${ }^{2}$

adrede: «del lat. ad directum, probablemente a través del cat. adret» (DRAE-1992), «del cat. adret, y este del lat. ad directum» (DRAE-2001);

borracha: «de or. inc.; quizá del cat. morratxa, redoma, con infl. de botella» (DRAE1992),

«quizá del cat. morratxa, redoma, con infl. de botella» (DRAE-2001).

2 Sólo se ha hallado una excepción, que coincide con la del apartado sobre orden de datos etimológicos: en niel se ha mantenido el adverbio seguramente (vid. supra, nota 1). 
Dentro de las hipótesis de etimología incierta o probable, es posible integrar otro grupo de préstamos que muestran una dirección segura del proceso de transferencia, pero no seleccionan una lengua concreta. En este caso, no ha habido ningún cambio formal en las dos ediciones. Se expresa del mismo modo. Si hay alguna modificación, se relacionará con las ya comentadas:

neto, ta: «del cat. o fr. net, o del it. netto» (DRAE-1992 y DRAE-2001);

bergantín: «del it. brigantino, a través del fr. brigantin o del cat. bergantí» (DRAE1992),

«del fr. brigantin o del cat. bergantí, y estos del it. brigantino» (DRAE-2001).

2.2.3. Voces con información comparativa: en ocasiones, como ya se ha avanzado, ante la imposibilidad de postular una procedencia concreta, la Academia se limita a facilitar datos de índole comparativa entre la forma del lema y la del catalán. El nombre de la lengua suele ir precedido por la abreviatura $c f$. (confer) en ambas ediciones, a veces al lado de otros comentarios como etim. disc. (etimología discutida) o de or. inc. (de origen incierto). En el DRAE-1992, podía encontrarse algún ejemplo del uso de como en lugar de $c f$., que se ha sistematizado en la edición de 2001:

mostachón: «probablemente, del lat. mustacĕum, como el cat. mostatxó» (DRAE1992), «quizá del lat. mustacěum; cf. cat. mostatxó» (DRAE-2001).

Teniendo en cuenta esta estructura contrastiva, conviene determinar si el objetivo consiste en describir una posible relación entre lengua donante y lengua receptora. Para solventar esta cuestión, se ha creído conveniente comparar ejemplos de este tipo con la información que acerca de ellos proporciona una obra especializada como el Diccionario crítico etimológico castellano e hispánico (en adelante DCECH), de J. Corominas con la colaboración de J. A. Pascual. En efecto, a modo ilustrativo, los siguientes ejemplos demuestran que esta fuente considera que son catalanismos evidentes lemas como aspillera y boira para los que el DRAE sólo proporciona información comparativa:

aspillera: «etim. disc.; cf. cat. ant. espillera (DRAE-1992 y DRAE-2001), «del cat. espitllera (o espillera) 'tragaluz', 'aspillera', y éste probablemente del lat. SPECULARIA 'vidrieras de una ventana'» (DCECH, s. v. aspillera); boira: «de or. inc.; cf. cat. y gall. boira» (DRAE-1992 y DRAE-2001), «palabra aragonesa tomada del cat. boira íd., procedente del lat. BOREAS 'viento Norte'» (DCECH, s. v. boira). 
Es posible concluir, por tanto, que la información comparativa sugiere, en ambas ediciones, la posible procedencia de estos vocablos. De todos modos, ya apunté en el comentario de la edición de 1992 que muchas hipótesis etimológicas de este tipo requieren una inmediata revisión para expresar de forma más concreta los puntos de partida de los correspondientes lemas y, aún más, teniendo en cuenta que algunos de ellos figuran como catalanismos indiscutibles en obras lexicográficas especializadas en la aportación del origen de las palabras.

\section{CAMbios DE CONTENIDO}

Las variaciones en el contenido de las hipótesis etimológicas de los préstamos del catalán que se han llevado a cabo en esta vigésima segunda edición deben interpretarse desde distintos puntos de vista. En primer lugar, dentro del campo de los préstamos del catalán, conviene observar si se ha variado el número de estadios evolutivos que se detallan, cuyos resultados metodológicos podrán hacerse extensibles al resto de palabras que comparten otros orígenes propuestos por el diccionario; y, en segundo lugar, es preciso desplazar la atención a un aspecto más general, relativo al contraste entre el número de catalanismos de las dos últimas ediciones y, en caso de que exista una diferencia cuantitativa, analizar si responde a un trabajo de revisión etimológica o si simplemente se explica por la adición o supresión de entradas lexicográficas.

\subsection{Número de estadios evolutivos de las hipótesis etimológicas}

En el comentario de la edición de 1992, indiqué que el diccionario no solía detallar la evolución etimológica completa de los lemas. Esta tendencia metodológica no tendría que interpretarse como un inconveniente. Al no tratarse de un diccionario especializado, no tiene por qué disponer de suficiente espacio para dar cuenta de las diferentes etapas evolutivas que ha seguido la palabra y de las lenguas que en ellas se han visto implicadas. El principal problema es que no siempre se ofrece el étimo inmediato, que sería lo esperable, sino el más alejado o los más alejados, como ya señaló Gutiérrez Cuadrado (2001-2002: 318) en su reseña. Este modo de proceder repercute directamente en el estudio de los préstamos, puesto que si se omite la información conocida acerca de la lengua o lenguas transmisoras, se están ocultando las diferentes influencias directas, románicas o no, que ha experimentado, en este caso, el español. Si se contrastan las dos últimas ediciones, es posible localizar algún ejemplo que ha contribuido al incremento del número de catalanismos -siempre y cuando los datos se hayan introducido con buen criterio-, pero nadie garantiza que no pueda haber otros que, sin más información que la del étimo lejano, sean imposibles de identificar: 
conrear: «del gót. garēdan, velar por, cuidar de, a través del lat. * conredare» (DRAE1992),

«del cat. conrear, este del lat. vulg. * corredare, y este del gót. *garēdan, velar por, cuidar de» (DRAE-2001);

tafetán: «del persa tâftè, literalmente torcido, variedad de tejido de seda» (DRAE1992),

«del cat. o it. taffeta, y estos del persa täfte, tejido» (DRAE-2001);

bocel: «del ant. fr. bossel» (DRAE-1992),

«del fr. ant. bossel» (DRAE-2001),

«del cat. bocell, y éste del fr. antic. bossel íd. (hoy bosel), quizá diminutivo de bosse 'bulto, joroba'» (DCECH, s. v. bocel). ${ }^{3}$

Si se parte de los catalanismos que aparecen en ambas ediciones, seguimos encontrando ejemplos sobre los que sólo se facilita el étimo inmediato -lo más esperable- y sobre los que se detalla la hipótesis etimológica por completo, además de los casos en que se ha ampliado la información acerca de etapas anteriores a la catalana:

cohete: «del cat. coet» (DRAE-1992 y DRAE-2001);

papel: «del lat. papȳrus, a través del cat. paper» (DRAE-1992),

«del cat. paper, y este del lat. papȳrus» (DRAE-2001);

correo $^{l}$ : «del cat. correu» (DRAE-1992),

«del cat. correu, y este del fr. ant. corlieu, de corir, correr, y lieu, lugar» (DRAE2001).

Es evidente que no hay uniformidad en el número de estadios que se incluyen en los paréntesis etimológicos y, en caso de ofrecerse sólo uno, no siempre se está convencido de si es el inmediato o el más lejano, es decir, de si se trata de un anglicismo, un latinismo o un helenismo, por ejemplo, o de si entre estos orígenes y el español, ha habido lenguas mediadoras.

\subsection{Número de catalanismos}

El número total de catalanismos localizados en la edición de 1992 era de 350, frente a los 375 de la de 2001. Convendrá observar si esta discreta modificación en cuanto al número de préstamos del catalán responde a un incremento de lemas o es resultado de la revisión de las diferentes hipótesis etimológicas.

Colón (1976: 173) considera este término arquitectónico como ejemplo de «francesismo», pero también insiste en que fue transmitido por el catalán. 
3.2.1. Variación en el número de entradas lexicográficas. Si se contraponen los corpus de catalanismos de las dos últimas ediciones del DRAE, puede observarse que, desde el punto de vista cuantitativo, se han producido tanto supresiones como adiciones de lemas.

En esta vigésima segunda edición, se han excluido 15 palabras que en la anterior se presentaban como préstamos indiscutibles del catalán. Cabe indicar, sin embargo, que la mayoría de ellas poseía marcas diacrónicas (ferrer, mege, naochero y vincle -ant.-), diatópicas (capsueldo, crébol y desgay -Ar.- y jeja-Lev.-) o ambas (batifulla y frao (ant. -Ar-- y marmesor-ant. Murc.-). Sólo en cuatro ocasiones no hallamos marcas, pero estas se deducen de las definiciones que para los respectivos préstamos se proponen ( mas $^{2}$-Cataluña-, destre -Mallorca-, carlán -antiguo, Aragóny mercantivol -antiguo-). Estas supresiones se explican por la decisión que adoptan los académicos en el momento de valorar el número de palabras que no debe aparecer en la siguiente edición del diccionario: es lógico que escojan vocablos que han dejado de utilizarse o cuyo uso es extremadamente restringido o quizá propio de otra lengua peninsular.

En este mismo proceso contrastivo, se han contabilizado casualmente 15 adiciones. La mayoría de estos nuevos préstamos pertenecen al lenguaje gastronómico (banda ${ }^{3}$-arroz a banda-, botifarra, escalivada, escudella, fideuá, fuet, tortel y ventresca). El resto está formado por dos sustantivos, uno referido a las fallas valencianas (ninot) y otro a un movimiento intelectual (novecentismo), por dos adjetivos (chafardero y macarra) y por tres palabras con marca diatópica (barcella-Val.-, cadireta -Val.- y detal-Ven.-). No considero adecuada la inclusión de los dos valencianismos indicados, puesto que son representativos de una variedad del catalán y no de nuevos elementos léxicos integrados en el vocabulario español.

3.2.2. Revisión etimológica. Prescindiendo de los lemas que acaban de comentarse en el apartado anterior, es posible organizar los restantes en tres grupos distintos, según si sus etimologías se han modificado (dos primeros) o si permanecen inalteradas (tercero).

3.2.2.1. Se ha hallado un grupo de 20 lemas considerados, en la edición de 1992, catalanismos indiscutibles (bacín, cartel $^{l}$, encanto ${ }^{2}$, galdrufa, gamba ${ }^{2}$, sorra $^{2}$, talayote ${ }^{l}$, tarin y zarpar) $)^{4}$, probables (mojera y tonel) o bien voces con mera información comparativa referente al catalán (alcabota, almodrote, ancorca, atobar, cañivete, cap, fríjol, merar y mercader), que no se tratan del mismo modo en la de 2001: se ha

4 En el caso de zarpar se ha cambiado la hipótesis de catalanismo por la de italianismo que propone el DCECH (s. v. zarpar), en cuyo artículo lexicográfico se argumenta explícitamente por qué no es aceptable la mediación catalana. Para un completo comentario al respecto, vid. Prat Sabater (2000: 2294). 
suprimido la transferencia catalana o cualquier vínculo con esta lengua. El objetivo de esta comunicación no es el de profundizar sobre los cambios llevados a cabo en estas palabras, pero, a mi modo de ver, resulta adecuado contrastar estas modificaciones con el tratamiento que les otorgan otras fuentes, en especial, el $D C E C H$ : este diccionario especializado considera que atobar, encanto ${ }^{2}$, gamba ${ }^{2}$, mercader, sorra ${ }^{2}$, talayote $^{l}$ y tarín son catalanismos indiscutibles. Convendría conocer las razones por las que la Academia ha propuesto un origen diferente para estas palabras con objeto de poder contrastarlas con las justificaciones que para ellas propone el $D C E C H$. Colón, que se ha dedicado al estudio del léxico catalán, castellano y románico, está de acuerdo en que sorra ${ }^{2}$ se juzgue préstamo del catalán (2002a: 45) y en desacuerdo en que atobar se considere del mismo modo (1987: 73).

3.2.2.2. Es posible ofrecer la cantidad de 45 nuevos préstamos del catalán, que no se consideraban como tales en la edición de 1992:

- 10 carecían de paréntesis etimológico (DRAE-1992). En el DRAE-2001, seis se presentan como catalanismos indiscutibles (bacoreta, bayoco ${ }^{2}$, boja ${ }^{l}$, boje ${ }^{l}$, carretón y ringlera $)$, dos como catalanismos no seguros $\left(\right.$ bol $^{3}$ y mero $\left.{ }^{l}\right)$, uno como catalanismo indirecto (benzoe), transmitido al español por medio del bajo latín, y otro con información comparativa referente al catalán $\left(\right.$ mongo $\left.^{l}\right)$.

- 4 se consideraban de origen incierto (de or. inc.), sin más comentario (DRAE1992). En el DRAE-2001, se halla un préstamo indiscutible del catalán (lisa), un arabismo de transmisión segura, pero no determinada (catalana o italiana, en el caso de mogollón) y dos voces con información comparativa referente al catalán (buñuelo y tojo $^{3}$ ).

- 1 era de etimología discutida (etim. disc.), sin más precisión (DRAE-1992). En el DRAE-2001, es catalanismo indiscutible (naipe), procedente, en última instancia, del árabe.

- 18 presentaban el étimo más lejano (DRAE-1992). En el DRAE-2001, se agrega el étimo inmediato. Es posible organizar la ejemplificación del siguiente modo: arabismos con transmisión catalana segura ( balda $^{3}$, jácena y nácar) o probable (alambor ${ }^{2}$, fustete, jaloque y siroco), germanismos con transmisión catalana segura (camarlengo, conrear, garba, grapa ${ }^{l}$, guaita y rengle) o probable (guante), voz descendiente del latín con transmisión catalana probable $\left(\right.$ balso $\left.^{I}\right)$, voz procedente del persa con transferencia catalana o italiana (tafetán) y dos voces más del alto alemán que han pasado a ser catalanismos indiscutibles (esquife y melsa). 
- 6 eran representativas de un origen, que se ha visto modificado: noque y ceje eran arabismos (DRAE-1992), mientras que ahora son catalanismos, procedente, el primero, del bajo latín, y acompañado, el segundo, de información comparativa acerca del francés; rabassa morta se presentaba como descendiente del latín (DRAE-1992), frente a la consideración actual de expresión catalana (expr. cat.), sin más comentario etimológico; encante era derivado de una forma española ( $D R A E$-1992), en cambio en la última edición se ofrece como catalanismo directo; en la edición de 2001 son probables catalanismos bojar (en el DRAE-1992, de probable procedencia neerlandesa), pantalla (en el DRAE-1992, con información comparativa referente al portugués) y babazorro (en el DRAE-1992, formado a partir de valvasor, lema sin paréntesis etimológico).

- 5 eran representativas de un origen al que, modificado o no, se le ha agregado información comparativa referente al catalán: abete ${ }^{l}$, garbillo y rachar eran descendientes del latín (DRAE-1992), mientras que, en el $D R A E-2001$, para el primero sólo se especifica $c f$. cat., al igual que para el segundo aunque, en este caso, se matiza que es un arabismo; el tercero (rachar) sigue siendo derivado del latín, a pesar de que en el DRAE-2001 esta información se acompaña con un «cf. gall. port. rachar y cat. asclar»; ufano era un germanismo indiscutible ( $D R A E$-1992), mientras que ahora es sólo probable y se incluyen datos comparativos referentes a las lenguas provenzal y catalana; por último, amenazar sigue siendo derivado de una forma española, pero en el DRAE-2001 se especifica que su empleo en la $3^{\text {a }}$ acepción ('conducir, guiar el ganado') que, de hecho, está desusado, está relacionado con el catalán («por las amenazas y voces con que suele conducirse; cf. cat. menar»).

Si se contrastan estas modificaciones con el contenido de las palabras de este grupo que se encuentran en el $D C E C H$, se observa que esta obra lexicográfica detalla que son indiscutibles préstamos del catalán balda ${ }^{3}$, balso $^{1}$, boja $^{1}$, bojar $^{2}$, bol $^{3}$, camarlengo, ceje, encante, esquife, garba, garbillo, guaita, jácena, lisa, melsa y noque; y catalanismos probables babazorro, bayoco ${ }^{2}$, carretón, conrear, grapa, guante, jaloque, mero ${ }^{1}$, pantalla y ringlera. Después de la lectura atenta de las justificaciones que propone el diccionario etimológico y de la opinión que para algunas de estas voces facilita Colón (esquife, jácena y melsa), ${ }^{5}$ es posible concluir que pueden con-

5 Vid. Colón (1967: 229 y 2002b: 39) para esquife; Colón (1968: 1925) para jácena; y Colón (1976: 88, 1991: 71 y 2002b: 38) para melsa. 
siderarse préstamos seguros del catalán balsol, ${ }^{l}$ bja $^{l}, b_{o j a r}{ }^{2}, b^{2} l^{3}$, encante, esquife, jácena, lisa, melsa y noque. ${ }^{6}$ Para el resto, es imprescindible el hallazgo de nuevos datos que corroboren de forma absoluta dicha transmisión y que justifiquen, por tanto, la condición de catalanismos que se les atribuye en la vigésima segunda edición del $D R A E$.

3.2.2.3. Es importante destacar que hay un número muy significativo de lemas $\sin$ modificación de contenido etimológico en ambas ediciones (puede haber cambios formales, pero no de contenido). Todos ellos siguen siendo préstamos del catalán. El número total asciende a 315 .

Para 20 de estos préstamos sólo se facilita información comparativa referente al catalán (alufrar, amoratado, armatoste, aspillera, beque, bergante, boira, borde ${ }^{2}$, burjaca, capizana, carraza, cariz, chafaldete, cimbra, combés, dita ${ }^{l}$, empeña, galdido, juarda y regala). Según el $D C E C H$, son préstamos indiscutibles del catalán aspillera, bergante, boira; beque, capizana y borde ${ }^{2}$. Este diccionario sólo justifica la transmisión de los tres primeros mediante los criterios cronológico, fonéticocronológico y relativo a la extensión geográfica, respectivamente. Son catalanismos probables armatoste, burjaca, cariz y dita ${ }^{l}$. El resto de ejemplos no están incluidos en esta fuente etimológica o bien no se consideran catalanismos.

Según el DRAE-2001, 32 lemas, que no han sufrido modificación etimológica, siguen considerándose catalanismos probables (adrede, ancorel, andarivel, argén, argue, avería ${ }^{2}$, bel, bergantin, bochin, borracha, carraspique, cinglar ${ }^{2}$, dalle, elmete, envite, escabel, escamel, estuque, flechaste, greuge, linaje, metal ${ }^{1}$, morel de sal, mostachón, oraje, peaje, pelitre, percha ${ }^{l}$, retrete, salín, salitre y sastre). El DCECH no recoge elmete ni salín, y no propone transmisión catalana para adrede, bel, cinglar $^{2}$, ni mostachón; coincide en que son probables catalanismos argén, carraspique, dalle, envite, escabel, estuque, flechaste, morel de sal, peaje, pelitre, perchal y sastre; pero considera que son préstamos seguros del catalán ancorel, andarivel, argue, averia ${ }^{2}$, bergantin, bochin, borracha, escamel, greuge, linaje, metal ${ }^{l}$, oraje, retrete ${ }^{7}$ y salitre. Sobre estos últimos, se aportan argumentos para consolidar la transmisión de linaje (fonética), andarivel (cronología), bergantín (fonética y cronología), avería (fonética, cronología y campos semánticos de marinería y comercio), metal ${ }^{l}$ (historia y contenido semántico) y bochín (frecuencia de uso). Colón (1967: 235) muestra acuerdo en la consideración de catalanismo indiscutible de esta última voz, pero considera que linaje es sólo probable puesto que halla datos textuales que hacen pensar en una posible mediación francesa u occitana al lado de la catalana (Colón 1967: 234).

${ }^{6} C f$. Prat Sabater (2003 y 2004).

7 Colón está de acuerdo en que esta palabra es catalanismo. Cf. Colón (1967: 219 y 232; 1968: 1914; 1976: 271, n. 39 y 1981: 201). 
Los 263 lemas restantes sin modificación en las dos últimas ediciones del $D R A E$, siguen presentándose como catalanismos seguros. El DCECH coincide mayoritariamente en esta solución: acotar ${ }^{3}$, alioli, amprar, añoranza, añorar, avellanate, bajel, bajoca, baladre, banderola, barraca, bastaje, borraja, brazola, brocatel, brollar, buido, butifarra, camota, cantimplora, capicúa, carquiñol, celindrate, ceprén, chácena, chuleta ${ }^{1}$, chulla $^{1}$, clavel, clavellina, clota, codoñate, conceller, confite, congoja, convite, cortapisa, crisol, cuartera, cuarterada, derrería (a la ), doncel, embornal, embuñegar, empeltre, empesador, entremiche, esclafar, escoa, esquirol, estoperol, estrepada, faena, fajol, fango, fleje, flojel, foja ${ }^{2}$, fona, fonébol, forastero, forcejar, formalete, francalete, frazada, freo, fuñar, gandaya ${ }^{2}$, genol, gobén, gobernalle, granel $(a \sim)$, grao, grupada, jamurar, jaquir, libán, litera, loguer, lonja ${ }^{2}$, malcoraje, mancha ${ }^{3}, \underline{m a n i g u e t a, ~ m a n u e l l a, ~ m a r g a l l o ́ n, ~ m a s a d a, ~ m a s i ́ a, ~ m e l i s, ~ m e n g e, ~}$ micer, mirrauste, mojel, molla, molsa, moscareta, moscatel ${ }^{1}$, moscatel ${ }^{2}$, mosén, mosqueta, muelle ${ }^{2}$, mújol, nao, naucher, nevereta, nolit, orate, orenza, orgullo, oriol, oropimente, osta, paella, pagel, pajarel, palafrén, palangre, palmejar, panoli, papel, pavorde, payés, pelaire, perchel, perlongar, perno, perol, perpunte, pésol, picaporte, pinjar, piular, placer ${ }^{3}$, poncella, porche, preboste, prensa, proejar, proel, proís, quijote ${ }^{1}$, rapa, rape ${ }^{2}$, remiche, retal, riel, rozagante, salicor, sardinel, semblante, semblar, seo, serpol, soler ${ }^{l}$, somatén, sor ${ }^{l}$, sosa, tercerol, tirabeque, trabucaire, trébol, trenque, treo, truque, viaje $e^{2}$ tusón ${ }^{8}$. La lectura atenta de los trabajos de Colón, en los que incluye el análisis de bastantes voces de este grupo, y el estudio detenido y crítico de las justificaciones que aporta el $D C E C H$, con la valoración de si utiliza suficientes argumentos o no para consolidar la hipótesis de transmisión, han permitido concluir que los que aparecen subrayados en la lista anterior pueden considerarse sin lugar a dudas préstamos del catalán. ${ }^{9}$

El DCECH considera catalanismos probables a algunos otros préstamos del grupo de lemas que no han sufrido ningún cambio en las dos últimas ediciones del DRAE: adempribio, aguaitar, albergue, amainar, arel, arganel, atiparse, burdel, capolar, carquerol, castañola, choca, cimbel, coca ${ }^{5}$, cohete, corda (estar a la $)$, cordel, correjel, correo ${ }^{1}$, costa $^{2}$, dátil, desgaire, dosel, escarola, fornel, fornir, gresca, hordiate, lagotero, maitines, manjar, metalla, miñón ${ }^{1}$, molde, neto, niel, novel, palenque, pebete, petar $^{l}$, pincel, porcel, roquete ${ }^{l}$, salvaje, serviola, usaje y viaje ${ }^{l}$. En otros casos, puede ocurrir que el $D C E C H$ no recoja las voces o bien que no ofrezca para ellas la hipótesis de catalanismo: absenta, arreo ${ }^{2}$, bagre, baldrufa, ballener, boj $^{1}$, bou, bovaje, cairel, cajel, cajín, calonge, cantel, canute, capel, capitol, capitoste, carrafa, chamelo, charnego, chueta, corondel, ensaimada, escomesa, escultismo, espinel, falla ${ }^{3}$, farte,

8 En esta y en el resto de listas ofrecidas en esta comunicación, se ha mantenido la lematización del DRAE-2001.

9 Cf. Prat Sabater (2004). 
formaleta, fuchina ${ }^{2}$, gros, mariol, masovero, mojada ${ }^{2}$, moncheta, musola, pansido, percanzar, pilatero, piñonate, plantaje ${ }^{2}$, pota, pote, rabasaire, reo ${ }^{2}, \mathrm{retel}, \mathrm{rol}^{2}$, taula, traite, vellutero y zadorija. Es preciso que se siga investigando sobre estas palabras para concretar de un modo mejor su procedencia con las debidas justificaciones, tanto lingüísticas como extralingüísticas.

\section{CONCLuSIÓN}

Realizado el contraste sobre la información etimológica de los préstamos del catalán incluida en las dos últimas ediciones del DRAE (1992 y 2001), es posible concluir que se han producido cambios, aunque quizá no todos los que se hubieran deseado.

Desde el punto de vista formal, se ha sistematizado en su totalidad la presentación de los datos del paréntesis etimológico, imprescindible en una época en que los medios informáticos permiten, en este sentido, simplificar y prácticamente sustituir el trabajo manual. Se ha renovado de forma positiva, por tanto, la metodología tradicional.

En cuanto al contenido etimológico, se han producido dos tipos de variaciones: la primera de ellas, referida al número de estadios evolutivos de las hipótesis etimológicas, resulta interesante siempre y cuando se hayan solucionado los casos que requerían la especificación del étimo inmediato. No considero relevantes los ejemplos en los que se han ampliado los datos sobre estadios anteriores. Si puede ser discutible la inclusión de hipótesis etimológicas en un diccionario general monolingüe (aunque para la Academia sea una tradición), lo es más aún la pormenorización de las diferentes etapas evolutivas de cada préstamo cuando la mayoría de usuarios puede ver satisfecha su curiosidad sobre el origen de las voces con la procedencia más cercana. Si se necesita más información, puede recurrirse a un diccionario especializado.

La segunda variación de contenido está relacionada con el contraste entre el número de catalanismos de las dos últimas ediciones: la supresión de préstamos, tanto antiguos como de empleo muy restringido, es bienvenida porque un diccionario general no puede ser histórico, dialectal y de uso al mismo tiempo o, lo que es lo mismo, para que sea funcional, no puede representar la suma de varios diccionarios en uno solo ( $c f$. Gutiérrez Cuadrado 2001-2002: 302). De todas formas, lo más esencial debe ser la revisión etimológica: a pesar de que se hayan realizado algunas modificaciones, muchos orígenes que se presentan como indiscutibles siguen sin ser compartidos por otras fuentes más especializadas; permanecen, asimismo, lemas de transferencia no segura o con mera información comparativa referente al catalán, que solicitan un estudio más profundo. Un diccionario general, al no disponer de suficiente espacio para integrar ningún tipo de justificación etimológica, debería recoger, en mi opinión, las hipótesis de transmisión segura y avalada por otras fuentes. El resto tendría que reservarse para diccionarios o trabajos especializados. 


\section{REFERENCIAS BIBLIOGRÁFICAS}

Colón, Germà (1967): «Elementos constitutivos del español: catalanismos», en Enciclopedia lingüística hispánica, Madrid, CSIC, II, pp. 193-238.

- (1968): «Acerca de los préstamos occitanos y catalanes del español», en Antonio Quilis, ed., XI Congreso Internacional de Lingüistica y Filología Románicas, Madrid, CSIC, Revista de Filología Española, anejo LXXXvi, Iv, pp. 1913-1925.

- (1976): El léxico catalán en la Romania, Madrid, Gredos.

- (1981): «Contrastes léxicos en catalán, español e italiano», en Wolf Dietrich y Horst Geckeler, eds., Logos Semantikos. Studia lingüistica in honorem Eugenio Coseriu (1921-1981), Madrid-Berlin, Gredos-Walter de Gruyter, III, pp. 191-201.

- (1987): «Filologia, etimologia i fantasia: *atovar en el Curial i Güelfa», en Problemes de la llengua a València $i$ als seus voltants, Valencia, Universidad de Valencia, pp. 63-74.

- (1991): «Las relaciones del léxico aragonés medieval con el léxico catalán», en Actas del I Congreso de Lingüistas aragoneses, Zaragoza, Diputación General de Aragón, pp. 69-78.

- (2002a): «De arabismos interhispanos», en Para la historia del léxico español (I), Madrid, Arco/Libros, pp. 45-54 [reedición del artículo].

- (2002b): «Elementos constitutivos del léxico español», en Para la historia del léxico español (I), Madrid, Arco/Libros, pp. 19-44.

DCECH. Corominas, Joan y José Antonio Pascual (1980-1991): Diccionario crítico etimológico castellano e hispánico, Madrid, Gredos.

DRAE-1992. Real Academia Española (199221): Diccionario de la lengua española, Madrid, EspasaCalpe [ed. en soporte CD-ROM, 1995].

DRAE-2001. Real Academia Española (200122): Diccionario de la lengua española, Madrid, EspasaCalpe [ed. en soporte CD-ROM, 2003].

GutiérRez CuAdrado, Juan (2001-2002): «El nuevo rumbo de la vigésima segunda edición (2001) del Diccionario de la lengua española de la Real Academia», Revista de Lexicografia, viII, pp. 297-319.

Prat Sabater, Marta (2000): «Préstamos del catalán en el Diccionario de la Real Academia Española (1992)», en Ma. Teresa Echenique y Juan Sánchez Méndez, eds., Actas del V Congreso Internacional de Historia de la Lengua Española, Madrid, Gredos, II, pp. 2287-2300.

- (2003): Préstamos del catalán en el léxico español, Bellaterra: Universidad Autónoma de Barcelona, Servicio de Publicaciones (tesis doctoral digitalizada: http://www.tdx.cesca.es/tdx1114103-150818).

— (2005): «La influència del català sobre el lèxic castellà: visió diacrònica», Llengua \& Literatura, 16, pp. 363-387. 